\title{
A SOCIOLOGICAL AND STATISTICAL ANALYSIS
}

\author{
KIngsLey Davis*
}

\section{Part I. Sociological and Anthiropological,}

Theoretically the problem of the post-divorce child is universal-not only because divorce itself in one form or another is universal, but more profoundly because the child of divorce constitutes a potentially anomalous element in social organization. In most societies this potentiality is not allowed to express itself; instead, social institutions exist which take care of the child without undue turmoil. The peoples of Western civilization, on the other hand, have developed a peculiar institutional system that makes the problem very acute and hard to solve in practice. To understand why this is true one must compare the position of the child after divorce in different societies.

\section{Divorce and the Immediate Family}

Since it dissolves the immediate family (now generally believed to be always and everywhere a part of society), the act of divorce usually offends the sense of order and fitness in social affairs. Hence it is nearly always tolerated in fact but never approved in principle. When children are involved the antagonism to divorce is greater, because dissolution of the marriage runs counter to the main function of the immediate family-namely, the bearing and rearing of children. Having formed a union which is socially defined, which involves mutual rights and obligations, and which clearly has as its main function the rearing of children, the parents separate and thus deprive the child of its socially prescribed milieu. If he remains with one parent he lacks the other-a real loss, because each parent plays a necessary and complementary role in the child's life. If the parent with whom he stays remarries, the child falls into a stepchild situation. If he is shifted back and forth between the parents, he must adjust to two different domestic milieus, possibly two different stepchild situations, and must therefore run the risk of discontinuity in his emotional and intellectual development.

This description seems extremely obvious, but it appears so only because it describes the situation in our culture. To millions of people living in non-Western societies the description would appear ludicrous-not because it fails altogether to fit their social systems, but because it fits them only in an abstract or analytic sense.

* A.B., 1930, A.M., I931, University of Texas; A.M., 1933, Ph.D., 1936, Harvard Univcrsity. Associate Professor of Public Affairs, Princeton University. Author of Yourn IN THE Depnession (r935) and of contributions to sociological and anthropological journals. Associate Editor of the JounNAL op Lronz and Political Sociology, and Assistant Editor of the Amferican Socrological Review.

For generous and indispensable statistical aid, the writer wishes to thank Mrs. Klara von Neumann, and his wife, E. Jane Davis. 
Although the immediate family is a universal group, it is not instinctive; rather it is a cultural phenomenon, and as such its specific form, and above all its connections with the rest of society, vary tremendously from one social system to another. It happens that in countless societies the immediate family is so interwoven with other institutional groups that, in case of divorce, the children do not constitute a social problem. The break-up of the immediate family is the same as in our society, and the anomaly of the child's position is potentially the same, but actually the parents' relation to other persons-often to clansmen and joint householders-is such that the child continues largely under their care.

\section{Divorce in Primitive Society: The Ibo}

The success of non-Western societies in solving the problem of the post-divorce child is explained by their wider use of kinship groups other than the immediate family. With them the immediate family is not the sole, nor even the most important kinship unit. Instead the clan, the extended family, and the joint household serve as important parts of social organization and perform functions which with us are left either to non-kinship groups or to the immediate family. Let us take as an example the Ibo society of Southern Nigeria, whose divorce customs have been ably reported. ${ }^{1}$

The first thing to note is the nature of Ibo marriage. It is not an agreement between the two prospective mates, but rather a contract between the parents and more fundamentally the clans of the mates. Without the prior consent and agreement of the two parental families no marriage could take place. Secondly, the prospective groom or his family must pay a bride-price to the girl's relatives, without which the union would have no legal standing. Thirdly, in spite of the marriage, the husband and wife remain socially and religiously members of their respective clans. The wife joins her husband's family physically but not spiritually. She must participate in the economic activities of his household, and above all she must bear children for his clan. But her underlying allegiance remains with her own family, and she may at any time return to it. The bride-price is the compensation that her parents, having gone to the expense of rearing her, receive for the loss of her services. It is not the price of her person, as such, for she continues to belong to her clan, but the price of her services. In return she has obligations toward her husband and his family. He also has obligations toward her, and unless these are properly observed her services may be withdrawn. She does not share her husband's possessions, inherit any of them after his death, or hold any claim to the children borne by her. Her husband has the right to contract as many marriages as he or his family can afford, and since a man's prestige depends on his wealth, and his wealth is most effectively displayed by the number of wives, he will try to secure as many as possible.

\footnotetext{
1 Wieschhoff, Divorce Laws and Prastices in Modern Ibo Culture (x94I) 26 Journal of Negro HrsTORY, 299-324.
} 
Being a private contract between the two families, a marriage may be revoked at will by either side. If he is willing to forget the bride-price the husband may send his wife back for any cause whatsoever. On the other hand, the wife may not be able to leave her husband even for just cause if her family refuses to refund the bride-price. Only if she has good prospects of remarrying, which means that another man stands ready to pay her family the bride-price (which then is returned to the original husband), may she leave of her own free will.

One of the most frequent causes of the dismissal of Ibo wives is barrenness. If several years elapse without a child being born, the wife may be sent home and the bride-price recovered. If, on the other hand, the wife has fulfilled her duty by bearing at least two children, including one son, it is extremely difficult for the husband to return her to her parents and receive back the bride-price. The charge of barrenness often elicits the counter-charge of impotence. If the wife fails to conceive for some years after marriage, she or her family and possibly her husband may make arrangements for extra-marital relations. A child born under such circumstances is of course the property of the husband and bolsters the position of the wife.

Obviously in Ibo society there can be no question of the custody of the children when a marriage is dissolved. They belong to the husband's family. It was largely for them that the marriage was contracted and the bride-price paid in the first place. The question may be raised as to how they can be taken care of without their mother, but the truth is that the mother's care is not necessary. Since the household usually includes some of the husband's female relatives, perhaps other wives, there is little difficulty about rearing the children.

The case of the Ibo has been chosen because its handling of divorce is, in its major outlines, typical of that in many primitive societies. The marital relation is dominated by lineal kinsmen, and the custody and rearing of the children do not depend on the continuance of the immediate family. The fact that the Ibo are patrilineal in their clan organization means that the child is viewed primarily as a member of the father's clan. This is sometimes thought to be the most difficult case for post-divorce children in kinship societies, because of the young child's physical dependence on its mother. Actually in some patrilineal societies the children do remain with the mother while they are infants and are returned to the father at a later date. ${ }^{2}$

In matrilineal and matrilocal societies the problem is easier. There, after divorce, it is the father who must leave; the child belongs to its mother's clan and hence remains in the mother's household. ${ }^{3}$ No conflict arises between the biological attachment of young children to the mother and their sociological attachment to the

\footnotetext{
2 This is true of the Yaruba, neighbors of the Ibo in Nigeria, and of the Naron pcople and the Namib Bushmen of South Africa.

3 Examples are the Pueblo Indians of the Southwest, the Iroquois of the Northeast, the Bush Negrocs of Dutch Guiana, the Khasis of Assam, and the Minangkabau of Sumatra.
} 
father. This is one reason why divorce is usually easier in such societies. The following description of the situation among the Khasis is typical:

"In the event of a divorce the mother is always allowed the custody of the children. Divorces ... a are of common occurrence, the result being that children in many cases are ignorant of the names even of their fathers. For the mother, on the other hand, the children cherish a very strong affection, all their sympathies and emotions binding them closely to their mother's kin. . . . The great drawback attaching to divorce in ordinary communities, i.e. the effect it has on the lives of the children of the marriage, does not apply to the Khasis, for with them the children always live with their mother and their mother's family, which latter would be bound to maintain them."t

In societies where the emphasis on extended kin is bilateral rather than unilateral, or in which residence and descent are at variance, or in which other special conditions obtain, almost any conceivable rule may prevail with reference to the custody of children after divorce. Sometimes the children are divided equally, sometimes the boys are given to the father and the girls to the mother, sometimes the mother gets the younger, the father the older children. Generally, however, there is no major problem of adjustment, because, whoever gets him, the child is likely to live in intimate and stable relationship with other relatives, both male and female, who will perform the functions of the missing parent.

Although there are exceptions and occasional lapses, the general-rule among primitive peoples may be summed up in a quotation from an article on Sumatran cultures:

"[In Indonesia] among strictly patrilineal peoples, such as the Batak and the natives of Nias, all the children [of divorced parents] remain with the father. . . . Among sibless people the childern are divided between the parents at divorce, and among matrilineal peoples they naturally remain with the mother."'

\section{The Case of the Chinese}

Not only primitive but civilized societies may utilize kinship as an important principle of social organization. This was the case in China before the process of Westernization set in. The immediate family was subordinate in nearly every respect to the extended family. The mates were selected and the marriage arranged by the parents, and the couple usually lived with the parents of the husband. The young bride was subordinate to the older females in her husband's extended household, and the husband was subordinate to his grandfather, father, or older brother. The household was frequently quite large, so that the children were surrounded by adults other than their mother and father-notably by uncles, aunts, and grandparents. The husband could divorce his wife for numerous causes, of which one was barrenness and another disregard of his parents. The wife's right of divorce was virtually nil.

\footnotetext{
- Gurdon, The Krasis (19:4) 80-82.

'Loeb, Patrilineal and Matrilineal Organization in Stsmatra: The Batak and the Minangkabau (I933) 35 Amierican Anthropologist 16, at 45 ff.
} 
Divorce in China did not imply family disorganization in our sense of the word. Since the dominant kinship unit was the extended patrilineal kin, the dissolution of a particular marriage had little significance, for it took more than this to break up the entire kindred or even a particular household. Furthermore, concubinage and polygyny made divorce less disruptive, because if one consort were divorced the others could maintain the immediate family. In any case the child necessarily remained in the father's household, where he continued to find the milieu much as it had been before. . If divorce seldom occurred in Chinese society it was not because the dissolution of wedlock was considered "bad for the child," but because marital harmony did not depend primarily upon personal likes and dislikes.

In a kinship society, whether primitive or civilized, the immediate family is hardly an independent unit. It is the extended family which exercises the main influence, which has the privilege of choosing the mate, determining the residence, controlling the property, watching the morals, and in general managing the affairs of the young couple. The married pair either live with or near their relatives, and the children consequently grow up with the latter. Therefore if one parent is lost through death or divorce the child's domestic environment is not seriously disturbed. He tends to remain in the same household, among the same intimate relatives, feeling just as secure and loved as ever. Also, what might be called the principle of kinship substitution-usually operates-the principle that if one kinsman is lost, another is available to take his place. Such a principle is necessary if kinship is to form the basis of social organization, and it is embodied widely in the so-called classificatory type of kinship terminology, which calls different relatives by the same term (e.g. father and father's brother) because they may be functionally equivalent or capable of substitution. The principle means that the child is seldom left without some relative to function as a parent for him. Being familiar with this mechanism, he accepts it as a part of life. Also, since usually it is sociological rather than biological paternity that counts, the "stepchild" situation does not arise. Actually, so far as daily behavior is concerned, the child may have drawn little distinction between his parents and the other adults in the household anyway. It is therefore easy for him to make the adjustment when a parent is lost. Things remain for him pretty much as they were before.

\section{Divorce in the Small Family System}

One of the outstanding peculiarities of Western civilization, in contrast to the cultures discussed above, is the degree to which kinship has lost its social importance. At first sight this might suggest that divorce itself would have lost its importance, but such is not the case. The decline of kinship has affected the extended, not the immediate, family. The latter has lost some of its erstwhile functions in our mobile, urban, industrial society, but because it is virtually the sole remaining kinship unit it has acquired some of the functions formerly performed by other kinship relations. Its burden has therefore become heavy-perhaps too heavy for its inherently frail 
structure; and divorce, which dissolves the immediate family, has become a much greater problem, because it represents a threat to the family organization that remains.

With the principle of kinship substitution and the custom of the great household abandoned, the child of a deceased or divorced parent has as a rule nowhere to turn except to the other parent. He does not retain the balanced family life that a child in a kinship society is likely to have. He is therefore a "problem" in a much more pressing sense.

\section{Emotional Tension in the Small Family}

Having become the sole important kinship unit, the small family exhibits an unusual emotional concentration within itself. Its members, living apart from other kinsmen and surrounded by temporary acquaintances or strangers, can rely only upon themselves to share the feelings peculiar to blood relationship. The resulting intensity is sometimes extremely great, if not stifling. The loss of nonaffectional functions has further increased the importance of the family's emotional bonds at the same time that it has reduced the mutual cooperation in outside matters which would ordinarily support these bonds. Marriages, instead of being arranged by the elders on the basis of objective standards, are formed on the basis of romantic love and maintained on the strength of mutual likes and dislikes. The custom of having only one, two, or three children, plus the isolation of the parents from any other children than their own, increases the uniqueness and hence the emotionality of the parent-child relation. ${ }^{6}$ Consequently any marital discord not only affects the mates acutely but also involves the children. Husband and wife, as a compensation for marital unhappiness, unconsciously seek consolation, revenge, release, prestige, security, or what not in the children. The offspring in turn are victims of divided loyalty, emotional insecurity, and parental interference. This is why many experts believe that chronic discord is worse for the child than divorce; but the emotional intensity of the immediate family in modern society complicates divorce itself. It not only makes divorce more probable (because if things go wrong they go very wrong), but it also makes much harder the emotional readjustments of parents and children after divorce.

\section{The Equalitarian Principle and Custody}

Our reliance upon the immediate family is connected with another trait that aggravates the problem of the divorced child-namely, the equalitarian principle in wedlock. In a society where clans exist the child belongs either to his father's or his mother's clan. He cannot belong to both. Consequently in case of divorce there is little question as to the child's custody and residence. But in our system the child does not automatically belong to one parent. Instead he may belong to either one, and it is up to the court to decide which one. Furthermore, because the

'Kingsley Davis, The Sociology of Parent-Youth Conflict (1940) 5 AMerican Sociological. Review $523-535$. 
estranged parents have a potentially equal claim, they often compete for the affection and custody (though not for the support) of the child. The court must assume the role of arbiter. It must exercise its "discretion," but finds itself with few rules on which that discretion can base itself. The welfare of the child rather than the claims of the parents is supposed to be the goal, but what is "welfare" to one judge is apt to differ from what is "welfare" to another.?

That parents compete for custody of the children is suggested by the results of Marshall and May's study of cases in Maryland and Ohio. They show that the mother generally gets the children, but that this is because she is usually the plaintiff. When the father is the plaintiff he gets custody more often than she, as Table I reveals. ${ }^{8}$ There is thus a tendency to award custody to the "innocent" party, al-

Table I

\section{Disposition of Custody in Maryland and Ohio Cases: Percentages}

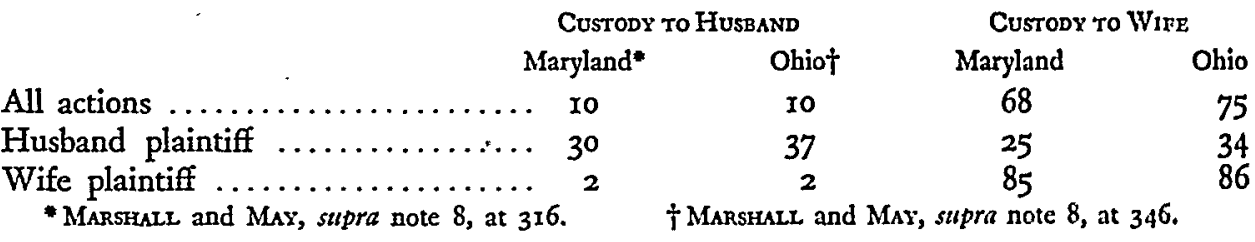

though this apparently has little to do with the welfare of the child. There is also a tendency for the mother to get custody oftener when the children are girls, the father when they are boys-a fairly frequent pattern in other societies. Less than five per cent of the Ohio cases involve division of the children between the parents, although provision is usually made whereby the parent not receiving custody may visit, or be visited by, the children, in which case there is a sort of de facto mixed custody. The facts indicate that a majority of the children of divorced parents in this country are living with their mother. This conclusion is substantiated by a study of high school students whose parents have been divorced. ${ }^{9}$ Thirty-two per cent of these students did not remember their father's occupation as compared to only 8 per cent of the students from non-divorced homes, indicating a surprising lack of contact with the father after divorce. Nevertheless, the parents have at the start an equal claim to the children, and the question of custody must be thrashed out anew in every case.

${ }^{2}$ An investigation made under the writer's supervision by a graduate student (Mrs. Mary Rice Morrow) at the Pennsylvania State College showed in Pennsylvania an almost complete lack of crystallized opinion among judges on this matter. They tended to award custody on the basis of unconscious or vaguely formulated rules of thumb. They seemed usually to believe that general principles could not be applied, because "each case is different." Only one-fourth of the replies admitted that changing customs and social values had any influence on the type of decision rendered. Therc was, however, a tendency to rely on the advice of social work agencies, which presumably supply more systematic evidence than "interested parties" can supply and contribute a professional definition of the child's welfare.

${ }^{3}$ Marshall and May, The Divorce Court, Vol. I, Maryland (1932) 31; Vol. 2, Ohio (1933) 346-350.

Weeks, Differential Divorce Rates by Occupation (1943) 2 I Social Forces 334*337. 
The competitive claims of husband and wife also emerge with reference to the support of the child. Since in our culture the father is supposed to support the child and the mother to care for it, the tendency of the court is to continue this division of labor after divorce. The fact that in a money economy a child can be supported at a distance, makes this arrangement seem convenient; but actually it presents an anomalous situation, because the father, deprived of the child's company, is nevertheless held economically responsible for him. The father thus receives an obligation without a reciprocal right. The one-sidedness of the arrangement is reduced, however, by the fact that woman's social role is more closely connected with the family than is that of the male, and that consequently his being deprived of the child's company entails less sacrifice than her being so deprived. Furthermore, the care of children is more burdensome and less easily evaded than their support.

\section{The Factor of Moral Stigma}

Although divorce in some form is permitted in all societies but encouraged in none, there are great differences in the degree of disapproval attached to it. American opinion has gradually changed from sharp to rather mild disapproval. ${ }^{10}$ The law, however, has retained in theory the older attitude; it bans divorce by mutual consent, stipulates that one party must have committed a wrong against the other, and thinks in terms of the "guilty" and the "innocent" partner. The moral condemnation of divorce has made, and still does make, the child's position more difficult than it would otherwise be.

To see the effect of moral stigma one should compare the child whose parents are separated by divorce with one whose parents are separated by death. The obvious difference that in one case only one parent remains alive while in the other

${ }^{10}$ Several systematic studies document this trend. BarNetT, Divorce and THE American Divorce Novex 1858-1937 (1939), finds a gradual transition from the nineteenth-century view of marriage as a divinely ordained end in itself to the twentieth-century view of it as a means to individual happiness, revocable if it does not succeed. Correspondingly there has been a growing tedency to regard divorce less as a moral and social evil and more as a personal experience, and to find the cause of divorce less in moral fault, with attendant blame of the parties concerned, and more in factors beyond individual control, such as early upbringing, unconscious personality traits, and social conditions. The shift of opinion was particularly noticeable after World War I, but it had been under way before that, and there was an especially marked change in the attitude toward remarriage after divorce. Curiously, the public interest in divorce has gone through four cycles of concern: first, over the very fact of divorce; second, over the effects of divorce on the children; third, over the question of alimony; and fourth, over the problem of post-divorce adjustment. The author, who finds that the first divorce novel by an American writer appeared in 1858 , thinks that perhaps divorce as a fictional theme may have spent itself after this last cycle of emphasis.

Koster, The Theme of Divorce in American Drama, I871-1939 (1942), traces the same shift of opinion in American plays. He too is able to date the striking change of attitude after World War $I$, and to document the transition from condemnation of an alleged social evil to toleration of a necessary though regrettable fact of individual experience.

Hart, Changing Social Attitudes and Interests, I Recent Social Trends (I933) 382, 414-4I7, uses refined indicators of approval and disapproval to gauge the public tolerance of easy divorce as reflected in magazine articles between 1905 and 1931 .

In recent years opinion polls, such as that conducted by Fortune in April I937 and the Ladies Home Journat in February 1938 , have shown in a more direct manner the liberalized public atutude toward divorce. 
both parents do, means that the divorce child may theoretically retain the contact and devotion of both parents. But this ideal possibility does not usually work out in practice, because the child, entangled by the closeness and intensity of the family bonds and the guilt complex of the divorce relation, is inevitably involved in the marital conflict. He is, after the divorce, the sole remaining link between the former mates, and consequently serves as the only instrument through which they can express their mutual resentment. The equalitarian principle which gives both of them rights in the child is conducive to his being used in this way, for if he divides his time between the two he must necessarily serve as a means of communication for them. A study of the divorce child in Nebraska showed that "often the parttime child is used as a weapon by one or both parents," that "in a few cases youngsters stated they had procured information for one parent against the other," that the situation afforded "the father an opportunity to find out how his former wife is spending his alimony, whom she is 'stepping out with,' and so forth," that "the mother may likewise question the child when he comes 'home' from father," and that in some cases "the child is bribed in order to get this information," and is thus taught by his own parents "to lie, spy, and blackmail."11

Playwrights and novelists have seized upon the dramatic element in the situation, usually portraying the child as an innocent victim of parental folly, living an unnatural and lonely life. ${ }^{12}$ Some of the sympathy undoubtedly reflects the genuinely difficult situation of the child, but one suspects that a good deal of it also reflects a moralistic bias. Since divorce is sinful, the child's lot must be painted as badly as possible in order to make the sin (in its consequences for the innocent offspring) seem as terrible as possible. Thus the moral stigma attached to divorce not only makes the child's position worse than it would otherwise be, but also requires that it be depicted as even more tragic than it actually is.

The child of divorced parents probably runs no greater risk of a stepparent situation than does the bereaved child. But he does run a risk, as the latter does not, of falling into two such situations, because both parents may remarry and he may be shifted from one household to the other. Actually this does not happen in a large percentage of cases, ${ }^{13}$ but it happens often enough to give point to novels and plays about "part-time children." The parents may have moved far away from each other and remarried in different social circles. The child may thus have to

21 Sullenger and Brownlee, Children of Divorce (1934) 9.

${ }^{12}$ See especially the following novels: Wilson, The Kenworthys (1925); Young, Custody, Cint.dren (I926); Johnson, Children of Divorce (1927); Wharton, The Children (1928); Sedgwick, Phitippa (1930); Spencer, The Inconpetents (1933); Savage, Sumarer Hail (1936); Eliot, Angel's Mirth (1936); and Pope, The Sentence of Youth (1936). For plays see Crothers, Mary the Thimd (r923) and Susan and God (1937); Ford, What Imagination Will Do (1928); and Atzas, WednesDAY's Child (1934). These are all cited and the plots discussed in BARNETT, op. cit. stipra note ro, especially at 96-I04, and Koster, op. cit. stipra note ro, in Chap. 5.

${ }^{13}$ It rarely happens for two reasons: first, probably less than half of the divorced persons who have children remarry; second, even when both parents happen to remarry, the child often remains in one houschold to the exclusion of the other. Custody is generally awarded to only one parent, though it is hard to say in how many cases the child regularly visits the other parent. 
divide his life between two radically different milieus, with a resulting confusion in his personality development. Because of bitterness between the estranged parents, he is apt to be under a taboo upon what he can say concerning events in the other household. Not only must he suppress part of his memories, but he must alter his personal habits and his family terminology each time that a shift is made. The situation is so new in our culture that no adequate terminology exists. What, for instance, is the new spouse of the divorced parent to be called by the child? "Stepmother" is hardly the correct term, because it implies that the child's real mother is dead. When the child talks to playmates about his father's wife, he accordingly has a hard time describing her, and outsiders frequently make mistakes that embarrass them and consequently him. ${ }^{14}$ Finally, he almost inevitably comes to prefer one household to the other, a fact taken by one parent as a breach of affection and an expression of a perverse devotion to the stepparent (perhaps the original corespondent) in the other household.

"The parents of the little boy who is now five were divorced when he was less than a year old. They were given joint custody. Thus every other week he was shifted from one grandparents' home to the other. From the statements of this little tot it is evident that his paternal grandmother was trying to instill in him a disfavor for his mother, and the maternal grandparents were endeavoring to blacken his father's reputation. However, this particular youngster favored his father's home. [When he returned from there he was restless and unruly for several days.]"15

One thing that makes any stepchild situation difficult is the mystical importance our culture attaches to biological parenthood. A "real" son or daughter must be one's "own." When the stepchild is the offspring of a person still living, who once had and (even worse) may still have the primary affection of one's mate, then the difficulty of loving the child is increased.

In some ways, therefore, the child of divorced parents is less fortunate than the bereaved child, but the reason lies chiefly in the emotional and moral implications with which our culture surrounds divorce. If spouses would divorce amicably, without blame or recrimination; if the law would cease to search for the guilty party; if the public would accept divorce as a natural occurrence-if, in short, all the attitudes and sentiments which control the institution of the family were abandoned, then the position of the child after divorce would not be anomalous, and writers of fiction would not feel obligated to paint his lot in somber colors. But in such a free and easy society there would be hardly any necessity of marriage, and hence no such thing as divorce. Mating would be on an informal basis, and the children would be cared for by whoever felt inclined, if anybody.

As previously mentioned, our peculiar institutional structure places considerable reliance upon the immediate family. Since this unit has lost many of its functions

16 There is not even a special term that designates the child of divorced parents. "Orphan" properly refers to a child of deceased parents. Only by a circumlocution, or by a coinage which seems in bad taste (e.g., divorce-child), can the child of divorced parents be designated.

${ }^{15}$ Sullenger and Brownlee, op. cit. supra note $\mathrm{I}$, at 9 . 
it can be broken without disturbing many aspects of society. Such dissolution does, however, affect seriously the rearing of children, which is an extremely important function in any society. Therefore, if the current social system for rearing children is to be maintained, divorce cannot become a matter of absolute indifference. There is, however, good evidence to indicate that easy divorce does not necessarily imply the disintegration of society. Many societies having high divorce rates are every bit as stable as many having low divorce rates. Egypt, for example, has an extremely high divorce rate (much higher than the United States), yet its fertility, the stability of its institutions, and the contentment of its people are apparently as great as they are in India, which has a low rate. In nineteenth-century Japan the divorce rate was much higher than in China, yet Japanese social organization was, if anything, more efficient. There is no reason to believe, therefore, that a highly tolerant attitude toward divorce in the United States will mean the decline and fall of our civilization. In practice we seem to be moving in the direction of easier divorce anyway, and as this movement continues the position of the child of divorced parents should improve. The only necessity is that some sort of social máchinery be worked out for rearing the child properly-a necessity hard to supply in our culture. Once this is accomplished the incidence of divorce is of little consequence to the stability of the larger society.

\section{Part II. Statistical}

To determine the number of children in the United States whose parents are permanently living apart, we should have to know, first, the number of divorces, annulments, desertions, and informal separations that occur from year to year, and second, the number of children affected by these events. Unfortunately our knowledge is deficient on all these points. The best statistics relate to the number of legal divorces, annulments, and separations, but even these are sadly inadequate, because Congress, although it often inveighs against divorce and frequently reiterates that the family is the foundation of society, does not allot sufficient funds to secure accurate marriage and divorce statistics. ${ }^{16}$ No official figures at all are obtainable on desertions and informal separations. Our attention, therefore, will of necessity be confined to legal divorces.

\section{The Number of Legal Divorces}

As is well known the divorce rate in the United States has risen steadily for as long as any information has been available. In 1940 it stood at two divorces per I,000 population, ${ }^{\mathbf{1 7}}$ the highest rate ever recorded in this country and six times as high as the average rate during the period $1867-187 \mathrm{I}$. Since 1940 the rate, as yet unreported, has probably risen still higher. In the accompanying chart the

${ }^{10}$ The establishment of a registration area for marriage and divorce has been suggested several times. A comprehensive plan along this line was well under way when it was interrupted by lack of appropriations caused by World War II. See Cohen, Centralized Collection of Marriage and Divorce Records and Their Uses (ig41) 31 Anierican Journaz of Publtc Healter.

${ }^{17}$ is Vital Statistics Special Reports (U. S. Bureau of the Census, 1942) 196. 
number of divorces per roo marriages from 1888 to 1946 is shown. (See also Table 4.) The rates up to $\mathrm{I} 94^{\circ}$ are based on official reports, ${ }^{18}$ those for I $94^{\mathrm{I}}$ and I 942 on a reported study of a few states, ${ }^{19}$ and those after 1942 on estimates made by the present writer. In I 940 the total number of divorces was approximately 264,000. In 1942 it was very probably above 300,000 . Such figures show that more than one out of every five marriages formed during recent years are ending ir divorce. By 1946 , if our estimates are correct, the proportion will approach one in three.

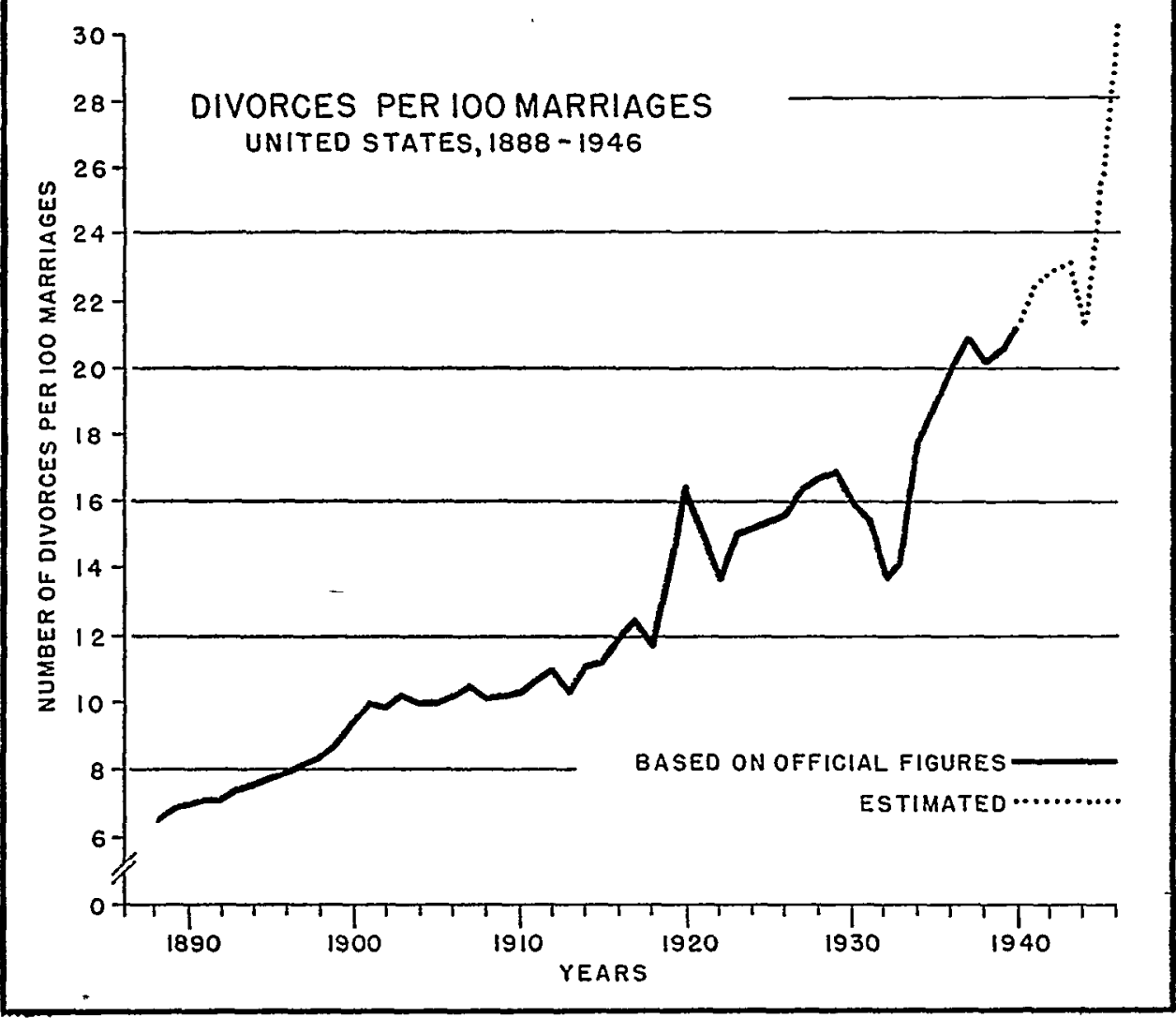

The Number of Children Affected by Divorce

Although the growing divorce rate implies an increasing number of children affected by divorce, it does not mean a proportionate increase. Several factors have combined to prevent this. In the first place, the birth rate has diminished. From I87I to I940, for example, when the divorce rate was increasing six-fold, the birth

${ }^{18}$ We took them, for 1888-1940, from Hart and Bowne, Divorce, Depression, and War (1943) 22 SOCIAL FORCES I92-I93.

${ }^{18}$ Ogburn, Marriages, Births, and Divorces (1943) 229 Ansals (of the American Academy of Political and Social Sciences) $27-28$. 
rate was dropping by more than fifty per cent. ${ }^{20}$ In the second place, divorce has tended increasingly to occur in the early years of marriage. During the period I867-1886 the most frequent number of divorces occurred in the seventh year of marriage. After that, from 1887 to 1906 , it occurred in the fifth. And during a subsequent period, I922-I932, it fluctuated between the third and fourth years, with the third holding the upper hand. ${ }^{21}$ Today it almost certainly falls in the third year. Naturally, the earlier the divorce the fewer the children, especially since divorce often involves a prior separation (quite long when the "cause" is desertion). In the third place, divorce occurs more frequently and the rate has risen more rapidly in the city than in the country, and it is precisely in the city that birth rates are lowest. ${ }^{22}$ In general it has been shown that divorce rates are greatest where birth rates are least. ${ }^{23}$ For all of these reasons the increased divorce rate has not meant a corresponding increase in the number of children affected. As a matter of fact the latter is only about one-third the number of persons getting divorces each year. ${ }^{24}$ Approximately two-thirds of the couples divorced are childless, and the majority of the remaining one-third have only one child. ${ }^{25}$ The conclusion therefore seems justified that much of the public alarm over the rising divorce rate, made in the name of the poor children, is exaggerated.

The same people who express alarm over the effect of the rising divorce rate on the children will, when they discover that a far greater percentage of childless than fertile couples get divorces, jump to the conclusion that, as one author naively puts it, "children tend to keep families together."20 They apparently reach this opinion by moralistic rather than exact reasoning, because the presence or absence of children has never in America been isolated as an independent variable in the causation of divorce. In order to measure its influence, age, duration of marriage, place of residence, economic status, and possibly other factors would have to be held constant. Until the data are available it is useless to assume the point as proven, no matter how righteous it may seem. In this connection it should be recalled that divorce is but one index of family disintegration. To ascertain the true effect of

\footnotetext{
${ }^{20}$ The estimated average birth rate during I87I-1875 was 37.0 per one thousand population. Lotla, Modern Trends in the Birth Rate (1936) I 88 AnNals (of the American Academy of Political and Social Science) 2. In $194^{\circ}$ it was 17.9. I5 Vital Statistics Specisi Reports (U. S. Bur. of the Census, 1942) 128.

${ }^{21}$ Cafien, Statistical Analysis of American Divorce (1932) 123; Marriage and Divorce 1932 (U. S. Bur. of the Census, 1934) 5; Monahan, The Changing Probability of Ditorce (1940) 5 Ansericsis Soctologicri Review 536, 543 .

${ }^{22}$ Mowrer, Family Disorganizatton (I939) 42-48; Willcox, Studies in AMericin Deagoraphy (1940) 351-354.

${ }_{23}$ Groves and Ogburn, American Marriage and Family Relationships (1928) 378; Li, Le Divorce en France (1936).

${ }^{24} \mathrm{C}_{\text {AHEN }}$ op. cit. supra note $2 \mathrm{I}$, at II3. For the period 1922 to 1932 the number of persons receiving divorces each year averaged 353,766 . Our estimate of the average number of children affected was $I 17,657$, which turns out to be 33.3 per cent of the number of divorcees. This is undoubtcdly a lower proportion than data for the nineteenth century, if available, would show, but because of the rise in the birth rate since 1933 it is probably fairly representative of the last decade.

${ }^{25}$ CAHEN, op. cit. supra note $2 \mathrm{I}$, at 113 .

${ }^{20}$ Bernard, American Family Behavior (1942) 98.
} 
childlessness on marital stability, desertions and informal separations would have to be taken into account. Marshall and May, who included desertion and non-support cases in their study of divorce records, found in Maryland that only 15.4 per cent of such cases involved childless couples, ${ }^{27}$ which is, of course, lower than the percentage of childless couples in the general population.

Official reports no longer give the number of children affected by divorce. However, figures were published for the period I922-1932, during which time slightly more than 36 per cent of the cases reported children. Making allowances for possible omissions, the average number of children affected by divorce each year during this period was approximately 117,500 . This was an extremely small number compared to the total child population; indeed, it was only 0.27 per cent of the number of children aged $0-18$ during the period covered. The average number of offspring per divorce was only 0.67 , and it was only 1.8 per case reporting children. Both figures exhibited a remarkable stability during the entire II-year period, the latter never varying from 1.8 until the last year (1932) when it dropped to $x$.7. In view of the stability of the number of children per divorce during the period, and certain grounds for believing it to be stable since then (e.g. a similar average birth rate), it can be used as a ratio for estimating the number of children affected by divorce in subsequent years, as follows:

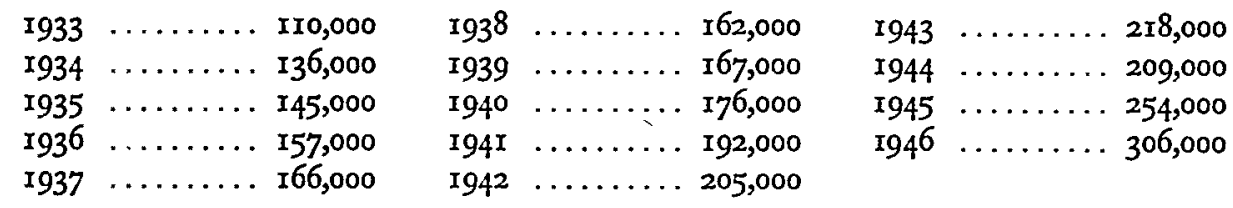

The I940 estimate represents $0.4 \mathrm{I}$ per cent of the children aged 0 -r8 living at that date. Thus the proportion was still less than half of one per cent.

\section{The Total Number of Children with Divorced Parents}

The knowledge that 150,000 to 200,000 children are affected by divorce each year in the United States does not tell us how many are living at any one time whose parents have ever been divorced. This latter figure, at any given time, is composed of all those children affected by divorce during the previous 18 years, less those who have died or who have passed age 18 . In order to estimate it, actuarial methods must be employed. When this is done the total number for 1940 turns out to be $1,533,000 .^{28}$ So far as the writer is aware, this is the only estimate of the kind ever made for the United States. Its accuracy, in view of the paucity of basic data, is only approximate, and it probably errs below rather than over the actual number.

${ }^{27}$ Op. cit. stpra note 8 , at 74 .

${ }^{38}$ The age distribution of children affected by divorce was assumed to be that reported in I MarshaLI and MAY, op. cit. supra note 8, at 79. The survival rates from the United States life table (1930) were then applied to each age, and each cohort was followed through until the year 1940 was reached, when a sum was taken of the number remaining in all cohorts at that year. The method, together with the method of estimating other figures in this article, will be more fully explained in a technical article. 
If correct, it means that 3.6 per cent of all children in the United States have divorced parents.

\section{How Old Are the Children}

Because divorce occurs more often in the early years of marriage, the majority of the children at the time of divorce should fall in the young ages. This proves true in Marshall and May's study, as Table 2 shows.

\section{Table 2}

The Percentage Age Distribution of Children at the Time of Their

\section{Parents' Divorce}

COMPARED WITH CHILDREN IN THE GENERAL POPULATION

\begin{tabular}{|c|c|c|c|c|}
\hline 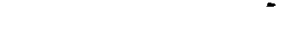 & \multicolumn{2}{|c|}{ Maryland Children } & \multicolumn{2}{|c|}{ OHIo Children } \\
\hline AGE & $\begin{array}{l}\text { Divorce } \\
\text { Sample }\end{array}$ & $\begin{array}{c}\text { General } \\
\text { Population }^{b}\end{array}$ & $\begin{array}{l}\text { Divorce } \\
\text { Sample }\end{array}$ & $\begin{array}{c}\text { General } \\
\text { Population }\end{array}$ \\
\hline $0-4$ & 27 & 24 & $3^{I}$ & 24 \\
\hline $5-9$ & $3^{8}$ & 25 & $3^{x}$ & 24 \\
\hline IO-I4 & 22 & 28 & $2 \mathrm{I}$ & 28 \\
\hline $15-18$ & I3 & 24 & $r_{7}$ & 24 \\
\hline Total...... 0-18 & IOO & $100^{\circ}$ & 100 & 100 \\
\hline
\end{tabular}

In contrast to this group, the total of one and a half million children whose parents have ever been divorced, as estimated for 1940 , have an older age distribution. This is shown in Table 3.

Table 3

The Percentage Age Distribution of All Children Whose Parents Have Ever Been Drvorced, r940

COMPARED WITH CHILDREN IN THE GENERAL POPULATION

$\begin{array}{ccc}\text { AGE } & \begin{array}{c}\text { Divorce } \\ \text { Children }\end{array} & \begin{array}{c}\text { Children in General } \\ \text { Populationt }\end{array} \\ 0-4 & 9 & 25 \\ 5-9 & 25 & 25 \\ \text { I0-I4 } & 35 & 27 \\ \text { I5-I8 } & 31 & 23 \\ 0-18 & \text { I00 } & \text { I00 }\end{array}$

Total........ 0-18 .

* Estimated by the method described, supra note 28 .

† Sixteenth Census of the United States (U. S. Bur. of the Census, 1940) 4 Population, Part 1, 8. 
Future Trends

If certain assumptions hold true the divorce rate can be predicted a few years in advance. But unfortunately, even when the assumptions hold in a general way they never do so in detail. Consequently the best one can do is an estimate that will, with a little luck, be fairly close to what actually happens; and the worst is an estimate that will prove completely wrong because the assumptions did not represent reality.

One plausible assumption is that the variations in the present divorce rate will follow the same pattern as in the last war era. This does not mean that the rate will be the same as in 1916-rg20; on the contrary it will be higher. But it means that the departures from the secular trend will be proportionately the same as during the previous disturbance. It can be further assumed that preparation for war and the aftermath of war extend the influence of war over a longer time than the period of actual combat, thus enabling us to obtain an estimate covering several years.

Since the last federal report on divorces in I940, some information has been gathered from particular states. This suggests that the rate per I,000 population increased nine per cent from I940 to I94I, and seven per cent from I94I to $1942 .^{28}$ How much of this increase was due to prosperity (abnormally great in these years) and how much to war itself, is hard to say. Doubtless a part of the increase was due to the great number of marriages that took place two or three years previously. The marriage rate had risen steeply since 1934, partly because many unions postponed during the depression were finally taking place and partly because very young persons were feeling financially qualified for matrimony. ${ }^{30}$

The boom in marriages is significant not only for explaining the rise in the divorce rate during I94I and I942, but also for estimating a greatly increased rate after the war. The marriage rate reached a minor peak in 1937 , declined slightly in $193^{8}$ and 1939 , went up sharply in 1940 , went still higher in I94I, and reached an astonishing high in I942. In both I94I and 1942 it was higher than it had ever been in the known history of the country. ${ }^{31}$ In 1943 it declined slightly, and doubtless in 1944 it did the same, but from I940 through 1943 the rate was excessive. The extraordinary number of marriages during this time would, under ordinary circumstances, manifest itself in more divorce during I943-I946. The war, however, will

${ }^{20}$ Ogburn, lac. cit. supra note 19 .

${ }^{30}$ Stouffer and Spencer, Marriage and Divorce in Recent Years (1936), I88 Ansilis (of the American Academy of Political and Social Science) 56-69; Stouffer and Lazarsfeld, Research Memorandum on the FaMiLY in the Depression (1937) Chap. 6.

${ }^{31}$ Beginning with 1930, the actual marriage rates per 1,000 population were as follows:*

\begin{tabular}{|c|c|c|c|c|}
\hline $193^{\circ}$ & $\ldots \ldots$ & $\angle \cdot 01 \cdots \cdots \cdots \cdots g^{\varepsilon 6 \mathrm{r}}$ & 1940 & \\
\hline $3 I$ & $\ldots \ldots \ldots 8$ & fror $\cdots \cdots \cdots \cdots$ & 1941 & 12.6 \\
\hline & 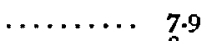 & $\begin{array}{l}\cdots \\
\cdots\end{array}$ & 1942 & I3.I \\
\hline & 8. & $\cdots \quad \measuredangle \varepsilon 6 \mathrm{I}$ & 1943 & II. 8 \\
\hline
\end{tabular}

$1934 \ldots \ldots \ldots 10.3 \quad 1938 \ldots \ldots \ldots$ I0.2

* Sixteenta Census of the United States, Marriages in the United States: 1914 to 1943 (U. S. Bur. of the Census, July 4, I944), Series PMI-I, No. I, 2. 
cause this result to be postponed until after hostilities are over. ${ }^{32}$ Immediately after the war, then, there will be a flood of divorces resulting from the accumulated effect of both the prewar marriage boom and the interim postponement of divorce.

But in addition to this quantitative basis for predicting a postwar divorce wave, there is also a qualitative basis-namely, the instable character of marriages formed under prewar, war, and postwar conditions. That such marriages are unstable was proved statistically in connection with the last war, it being shown that at least during all the years up through 1933 the marriages formed in 1919 and 1920 , and to a lesser extent in I9I7 and I9I8, gave rise to a disproportionate number of divorces. ${ }^{33}$ The causes of the instability are the special motives and conditions that, at such a time, govern mate selection on the one hand, and influence marital relations on the other.

During the preliminary period of preparation for war, young people tend to marry with even less rationality than usual. Sudden prosperity in the form of abnormally large wages gives them financial independence of their elders at a premature age. Increased mobility gives them release from primary group controls. The confusion of patriotism with both sex and love gives them a distorted conception of marriage as at once a duty to the nation and a means of immediate gratification. The pressure of wartime anxieties, such as nostalgia, insecurity, and fear of separation or death, gives them a pathological reliance on sudden marriage as a refuge. ${ }^{34}$ The exhilaration of new uniforms and of new and exciting ways in which the sexes are thrown together gives them a tendency to overlook the defects of persons known on short acquaintance. Finally, the boom in marriages itself gives them a collective stimulus toward matrimony. "Once the wave of war marriages gets under way, the movement generates its own motivating fervor," many girls fearing a dearth of men after the rush toward wedlock is over. ${ }^{3 t}$ In short, marriage becomes a fad, if not a craze, and ordinary precautions are thrown aside.

Insofar as rational motives assert themselves, they are likely to represent a mercenary adaptation to war conditions. The prospect of a liberal allowance from the government, of a substantial life insurance policy furnished by the government, and of pensions and bonuses, helps the girl consent. The widespread belief in the early stages that married men will not be drafted prompts many a hasty wedding. Such rational motives as these, plus the irrational ones just mentioned, lead to highly unstable unions; for they mean that the marriage is in many cases treated as a means for reaching an end which will either not exist in peacetime or will not be served by the continuance of this particular match.

\footnotetext{
${ }^{32}$ Divorces tend to be postponed during wartime for several reasons: ( 1 ) Couples living apart do not quarrel as often as those living together. (2) War separation often temporarily satisfies the purpose of a divorce. (3) The pressure of military duty, of war employment, and of war life in general allows little time for brooding over personal problems or tałing court action. (4) Soldicrs are not requircd to answer a divorce summons unless they wish to.

${ }^{38}$ Hall, The Instability of Post-War Marriages (1934) 5 Journal of Social Psychology, 523-530.

${ }^{34}$ Bossard, Family Problems in Wartime (1944) 7 Psrchatry 66.

3E Ibid.
} 
Most of these motives and conditions prevail also during the second and third periods of war-the period of actual conflict and the period of postwar readjustment. The marriage rate declines during the second period, but the few marriages that take place are as prone to instability as the earlier ones. Finally, after the war, in addition to the generally mobile and unsettled conditions, there are three factors in particular that contribute to ill-advised unions-first, the emotional and sexual intensity of contact after long separation; second, the feeling of moral and nervous release from war tension, and third the fulfillment of engagements made during the period of conflict. Also, most of the mercenary inducements mentioned above continue in operation.

War marriages are weakened not only by the factors governing the decision to marry and the choice of mates, but also by the conditions that affect them after the union is consummated. The separation of married couples by military service is especially damaging, because it lasts a long time, comes often in the earliest stage of married life (before there has been time for mutual adjustment), and places the two people in extremely different environments (where incompatible habits and points of view are acquired and new ties formed).$^{36}$ Also, by emphasizing loyalty to the nation rather than to the family, and courage rather than abstinence, war tends to loosen the controls over sexual morality. ${ }^{37}$ This new orientation tends to continue into the postwar era, but without the purpose or discipline of war; and, with the addition of other elements, the jazz-age begins. It is through these troubled times that the great number of marriages formed in the prosperous and exciting years before the period of actual combat must pass. Since their quality was not the best to begin with, a high percentage of them will inevitably wind up as casualties.

As a result of the excessive marriage rate before and after the war, of the hasty and ill-advised character of many war unions, of the adverse effect of war conditions upon them, and of the postponement of divorce during the period of actual conflict, the number of divorces during the period of postwar readjustment should, by far, exceed anything previously known in this country. Divorce itself will become almost a fashion. Many couples will want one not because they are really incompatible but because they feel entitled to it. Eventually most of the unsuccessful unions will have been dissolved and the divorce rate will drop. The rate, however, will not drop to the former level, because there is a secular increase that has been going on for decades and that showns no sign, as yet, of faltering.

\section{Estimates of Divorces and of Divorce Children, to 1946}

Assuming that the war will be over at the end of 1944 or the beginning of 1945 , the divorce wave should reach its crescendo in the latter part of 1945 or early 1946 .

\footnotetext{
${ }^{30}$ Bossard, stipra note 34, at 67-71. Bossard, War and the Family (1942) in Becker and Hitl,

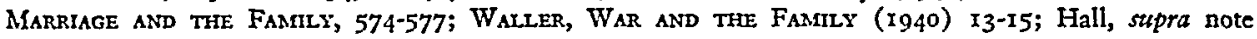
33 , at 528 .

${ }^{37}$ WaLLER, op. cit. supra note 36 , passim.
} 
Two writers on this subject estimate that the total rate for 1945 will be almost twice that of 1940 , and that, if continued, it will mean the dissolution of one-third to onehalf the marriages formed. ${ }^{38}$ Whereas in 1940 the number of divorces was 264,000 , these authors forecast that in 1945 it will be about 575,000 . This estimate seems excessive, but other methods also yield extremely large numbers. In Table 4 our own estimates are given (in italics), preceded by official figures back to 1927.

\section{Table 4}

\section{Divorces and Divorce Rates Per joo Marriages}

$$
\text { ז927-1946 }
$$

\begin{tabular}{|c|c|c|c|c|c|}
\hline Year & Divorces* & $\begin{array}{l}\text { Rate per roo } \\
\text { Marriages } f\end{array}$ & Year & Divorces" & $\begin{array}{l}\text { Rate per 1oo } \\
\text { Marriages }\end{array}$ \\
\hline I927 & I92,037 & 16.4 & 1937 & 249,000 & 21.0 \\
\hline 1928 & I95,939 & 16.7 & 1938 & 244,000 & 20.1 \\
\hline 1929 & 201,468 & I6.9 & I939 & $25 \mathrm{x}, 000$ & 20.5 \\
\hline 1930 & $x 91,59 x$ & I6.0 & 1940 & 264,000 & $2 \mathrm{I} \cdot 3$ \\
\hline I93I & 183,664 & 15.5 & $194 \mathrm{I}$ & 288,000 & 22.4 \\
\hline 1932 & 160,338 & 13.6 & 1942 & $\ldots \ldots \ldots$ & 22.9 \\
\hline r933 & 165,000 & $I 4.2$ & 1943 & 328,000 & $23 . I$ \\
\hline r934 & $\ldots \ldots \ldots \ldots 204,000$ & 17.8 & I944 & 314,000 & $2 I \cdot 3$ \\
\hline I935 & $\ldots \ldots \ldots \ldots 2 \times 2 \times 8,000$ & I8.9 & I945 & 382,000 & 25.5 \\
\hline$x 936$ & 236,000 & 20.1 & 1946 & $46 r, 000$ & 30.2 \\
\hline
\end{tabular}

* The divorce figures through 1940 are those officially reported. For 1941 and 1942 they are based on Ogburn's estimate, supra note 19, at 27, of the increase in the divoree rate per 1,000 population. For 1943-1946 they are obtained by assuming the same percentage increase from 1942 to 1943 as occurred from 1916 to 1917 , the same decrease from 1943 to 1944 as occurred from 1917 to 1918 , the same increase from 1944 to 1945 as occurred from 1918 to 1919 , and the same increase from 1945 to 1946 as occurred from 1919 to 1920 .

$\dagger$ The rates are based on the average number of marriages during the decade prior to the year in question. The marriages are those officially reported through 1943, and the calculations were made by Hart and Bowne, supra note 18 , up to 1940 . Since no official figures on marriage have appeared for 1944 or I945 at the time of writing, these were estimated by assuming the same variations as occurred in the last war; but the accuracy of these estimates has little effect on the ten-year average anyway.

It will be noticed that for 1946 our figure reaches $46 \mathrm{r}, 000$, in contrast to the peak of 575,000 estimated for 1945 by the two authors previously cited. Their estimated rate for 1945 is 38.3 per hundred marriages, whereas ours for 1946 is only 30.2 . In short, they estimate that over one-third, and we that slightly under one-third, of marriages will be ending in divorce. In 1936 , for the first time, one-fifth of the marriages were ending in divorce, and in 1945, according to our estimate, one-fourth of them will be doing so.

Now, having estimated divorces it remains to estimate the number of children who will be affected by divorce. This is extremely hazardous, not only because the birth rate has undergone variation, but because the statistical basis relates to the now distant period of I922-I932. However, as previously noted, the ratio of children to divorces remained fairly stable during that period. Also, the rise in the

${ }^{38}$ Hart and Bowne, Divorce, Depression, and War (1943) 22 SocinL Forces 194. 
birth rate in recent years has made the average birth rate since that time about the same as it was during the earlier period. It is therefore possible to assume the same ratio between divorces and children affected as obtained during 1922-1932, and in this way to estimate the number of children involved in divorce cases from 1933 to 1946. The results are presented in Table 5.

\section{Table 5}

Estimated Number of Children Affected by Divorce, 1933-1946

\begin{tabular}{|c|c|c|c|}
\hline Year & Children & Year & Children \\
\hline r933 & II0,000 & $194^{\circ}$ & 176,000 \\
\hline I934 & 136,000 & I94I & 192,000 \\
\hline I935 & $x_{45,000}$ & 1942 & 205,000 \\
\hline $193^{6}$ & 157,000 & 1943 & 218,000 \\
\hline 1937 & $\mathrm{r} 66,000$ & I944 & 209,000 \\
\hline I938 & 162,000 & 1945 & 254,000 \\
\hline 1939 & $x 67,000$ & ז946 & 307,000 \\
\hline
\end{tabular}

The calculations for years after 1940 are based on the estimated divorces given above. If for 1945 the number of divorces estimated by the Hart and Bowne method is used, the estimate of children affected rises to 382,000 . This represents a high estimate, and the figure of 307,000 in the table a low estimate, of the peak quota of children that will be involved in any one year's divorce cases soon after the war.

Again it should be emphasized that these estimates do not pretend to foretell the future in any exact sense. They merely attempt to give a rough idea of what one may expect to be the general trend. If they prove to be within 20 per cent of the truth, they will have served their purpose.

\section{ConcLusion}

In the United States, as in other Western nations, the child of divorced parents constitutes a relatively new, acute, and unsolved social problem. This is due primarily to the peculiar social structure that Western peoples have developed. It is not due, as many people believe, to the rising divorce rate. The divorce rate has risen steadily and is likely to rise still more, yet such a trend merely increases the incidence of, but does not create, the problem. There are societies in which the divorce rate is higher than in the United States, but where the problem of the divorced child hardly exists. In primitive or archaic kinship societies the allocation of the child to the mother's or the father's family is usually automatic, and the child has substitute parents and many kinsmen living with or near him; consequently, the adjustment after divorce is quite easy. Our society, on the other hand, has a small family system with little emphasis on extended kinship, with equalitarian rights of the parents in the child, and with intense emotional involvement in both the marital and the parental relationship. As a consequence the child's future must be decided in each divorce case by the discretion of the court, with few principles other than 
the vague "welfare of the child" to guide it. The parents often use the child as an instrument of mutual conflict. They also compete for his custody, though not for his support. The public exaggerates the disadvantages of the child's situation, and seeks to prove by this means that divorce itself is an evil. In our culture, therefore, the child of divorce is a social problem in the sense that the societal machinery for dealing with him does not operate automatically or satisfactorily. Though he is really better off than the child whose parent has died, he is more of a problem because his condition is felt to be somebody's fault, with all that this implies.

With the possible exception of the last two decades, the number of children affected by divorce each year in the United States has not risen as fast as the divorce rate. According to our estimates the number in 1940 was $176,000-$ only 0.4 per cent of the total number of children in the population. In the same year the number of children whose parents had ever been divorced was, by our estimate, I, 533,000 , which was 3.6 per cent of the total child population. Such figures are merely approximate, but may be sufficiently accurate to aid social agencies having to deal with the problem. It should be remembered, however, that these estimates relate only to legal divorces. The number of children affected by permanent desertion and separation, independently of the law, is entirely unknown, but the chances are that it is substantially larger than the number affected by divorce-yet the social problem is essentially the same, and perhaps worse.

For the future there seems every reason to believe that the divorce rate will climb steeply after the war, until approximately one-third of all marriages are being dissolved. Because of the recent rise in the birth rate the number of children affected will climb almost proportionately. The peak year (1945 or 1946) may see as many as 300,000 children involved in divorce cases.

The statistics, tentative at best, indicate the numerical extent of the problem. The sociological and anthropological analysis tries to show the causes of it. Neither approach, unfortunately, can give a certain answer to the two great questions of the future: In what ways will the social structure change so as to make the child of divorced parents less of a social problem? and when will the secular increase in the divorce rate reach a turning point? About the only certainty is that both changes are bound to eventuate sometime. It is doubtful if either can be accomplished deliberately by legal means, although the law will likely play a part. Since a high divorce rate does not necessarily threaten societal stability if ways are available for safeguarding the children, it may be that America will eventually have a divorce rate that will seem astounding by present standards. If so, it is safe to assume that the present chaos concerning the children will not then prevail. Some social mechanism will have been evolved for taking care of them. The remedy, therefore, does not necessarily lie in reducing the number of divorces. Divorce is here to stay. Instead, some means of neutralizing the effects of divorce on the child may be found by the creation of new institutional relationships that will replace the kinship bonds of primitive and archaic societies. 